\title{
AGE-RELATED CHANGES IN CORTICAL THICKNESS OF HUMAN ARCHICEREBELLUM
}

Article history:

Submitted 4 April 2019

Accepted 3 June 2019

\section{Tatiana Tsekhmistrenko ${ }^{1,2 *}$, Vadim Astashov' Valentin Kozlov', Yulia Antsyreva ${ }^{7}$}

\author{
${ }^{1}$ Peoples Friendship University of Russia (RUDN University), Moscow, \\ Russia \\ ${ }^{2}$ Institute of Developmental Physiology, Russian Academy of Education, \\ Moscow, Russia
}

*Corresponding Author: tsekhmistrenko2010@yandex.ru pontine nuclei are distributed within the vestibulocerebellum providing mediated connections of the cerebral cortex, red nucleus, tegmentum of midbrain, globus pallidus and other brainstem and diencephalic structures with the cortex of flocculonodular lobe. The direct efferent projections in turn are directed from the cortex of the flocculonodular lobe to the vestibular nuclei, exerting a direct inhibitory effect, in particular, on the neurons of Deiters' nucleus which is of great importance for the motor regulation involving spinal motor centers $[3,4,5]$. Such character of direct and mediated connections of the cerebellar nodule and flocculi indicates a significant role of the cortex of vestibulocerebellum as an integrative cortical center in formation of not only basic motor functions and postural control but also visual perceptual functions, spatial and self-orientaion perception $[6,7,8]$. Motor control mechanisms and organization of motion itself with participation of the vestibulocerebellum are formed gradually in the process of child development. As was shown earlier, the cortical thickness is an integral indicator of the structural changes of the cerebellar cortex in different periods of growth and human development [9]. The purpose of this study was to study changes in the cortical thickness in the flocculonodular lobe of the human cerebellum in different periods of growth and human development.

\section{MATERIALS AND METHODS}

115 cerebellums of people of both sexes, aged from birth to 20 years, who died from injuries not associated with brain damage, were studied. Collecting of the corpse material was approved by Ethics committee of the Institute of Age-related Physiology of the Russian Academy of Education (Protocol No. 3; 23/05/1996) and was carried out in the forensic morgues of Moscow and the Moscow Region. The material was grouped according to annual intervals. Pieces of the cerebellar cortex for histological examination were taken in the area of the nodule, the right and the left flocculus, fixed in 10\% neutral formalin, dehydrated in alcohols of increasing concentration and embedded in paraffin blocks. The cortical thickness at the apex of the cerebellar folium was measured on sagittal sections, 10- $\mu$ m-thick, Nissl-stained (with cresyl violet), by computer morphometry using 
BIOSCAN-AT and Image Tools programs $(\mathrm{NICH}$, USA). The sample size for each slice was at least 10 , for each preparation - at least 40 , for each age - at least 160 measurements. For indicators of cortical thickness in different age groups, the mean, the standard error and the confidence interval $[10]$ were calculated with a significance level of $\mathrm{P}=95 \%(\mathrm{p}<0.05)$.

\section{RESULTS}

In newborns the cortical thickness in the nodule area is $505.0 \pm 22.2 \mu \mathrm{m}$, in the right flocculus $-495.5 \pm 28.9 \mu \mathrm{m}$, in the left flocculus $403.83 \pm 17.0 \mu \mathrm{m}$. Thus by the time of birth, this indicator in the right flocculus and the nodule is 1.2-1.3 times greater than in the left flocculus. By the end of the first year of life, the cortical thickness in the nodule increases by 1.3-1.4 times; at age 3 years - by 1.7 times, at $7-8$ years - by $1.9-2.1$ times, compared to newborns. The highest values are observed in the nodule of children at the age of 8-11 years whose cortical thickness mean is from $924.4 \pm 38.2$ to $965.2 \pm 41.6 \mu \mathrm{m}$. However, by the age of $12-13$ years, a tendency towards a decrease in cortical thickness is observed in the nodule, and by the age of 14 , a significant decrease in this indicator is observed. The cortical thickness in the nodule of teenagers at the age of 14 and 15 is $830.7 \pm 29.9$ and $848.4 \pm 34.4 \mu \mathrm{m}$, respectively. In adolescents after 15 years of age, the cortical thickness mean in the nodule does not change, and by the age of 20 , it is $820.8 \pm 54.3 \mu \mathrm{m}$ (Fig. 1).

The cortical thickness in the right flocculus increases from birth to 12 months by 1.2 times, at 2 years - by 1.4 times, at 3 years - by 1.6 times, and at 7 years - by 1.9 times, compared to newborns. In children of age 9-11 years, the greatest rates of cortical thickness in the right flocculus are observed, the means are from $914.8 \pm 28.9$ to $960.6 \pm 38.4 \mu \mathrm{m}$. By the age of 12 , in the right flocculus, as well as in the nodule, there is a tendency towards a decrease in the cortical thickness, and by the age of 13 years, a significant decrease in this indicator is revealed. By the age 13 and 14, the cortical thickness in the right flocculus is $817.5 \pm 43.1$ and $821.2 \pm 50.2 \mu \mathrm{m}$, respectively. By the age of 15 , the cortical thickness in the right flocculus is $894.6 \pm 32.8 \mu \mathrm{m}$; it grows, compared to 13 years. After age of 15 years, the cortical thickness in the right flocculus stabilizes and by the age of 20 its mean is $875.8 \pm 33.2 \mu \mathrm{m}$ (Fig. 2).

The cortical thickness in the left flocculus from birth to 12 months increases by 1.6 times, at the age of 2 years - by 1.9 times, at $6-7$ years - by 2.1 times, compared to newborns. Thus the cortical thickness in the left flocculus from birth to 6 years grows more intensely than in the right flocculus. The cortical thick- ness in the left flocculus up to 3 years of age remains 1.1 times greater than in the right flocculus. Only by the age of 4 years the differences between them disappear due to increase in the cortical thickness in the right flocculus. By the age of 6 years, the cortical thickness in the left flocculus is $855.6 \pm 29.7 \mu \mathrm{m}$, and in the right flocculus $-854.3 \pm 39.8 \mu \mathrm{m}$. At the age of 7-8 years, the cortical thickness in the left flocculus remains stable, from 9 to 11 years it shows a clear tendency to decrease. At the age interval from 9 to 11 years, the cortical thickness in the left flocculus becomes 1.1-1.2 times thinner than in the right flocculus. By the age of 12-14 years the differences in the cortical thickness in the left and the right flocculus are gradually smoothed out. By the age of 15 , the cortical thickness in the left flocculus is $896.44 \pm 41.4 \mu \mathrm{m}$, in the right flocculus $-894.56 \pm 34.6 \mu \mathrm{m}$. After 15 years of age, the cortical thickness in the left flocculus, as well as in the right, stabilizes, and by the age of 20 its mean is $880.5 \pm 24.3 \mu \mathrm{m}$ (Fig. 3).

\section{DISCUSSION}

Each of the analyzed archicerebellar cortical zones, despite their phylogenetic homogeneity, is characterized by a peculiarity of the timing of changes in the cortical thickness. The peculiarities of the age-related changes in the cortex at the apex of the cerebellar folium in the region of arhicerebellum are well illustrated by polynomial curves with a high degree of confidence of the approximation (Fig. 1-3).

The obtained data allow identifying a number of gradual stages of age-related changes in the cerebellar cortical thickness in all investigated cortical loci: I - synchronous growth of the cortical thickness from birth to 3 years; II - heterochronic and heterodynamic growth from 4 to 9-11 years; III — asynchronous specialized changes in the cortical thickness from 12 to $14-15$ years; IV - stabilization of cortical thickness after 15 years. It is interesting to compare the revealed periods of age-related changes with the data on coordination abilities, parameters of which, closely related to vestibular regulation, are most intensively formed in children and adolescents at the age from 8 to 15 years $[11,12]$. This is also evidenced by data on improvement of postural regulation in children and adolescents with age, as well as by data on the strengthening of the cerebellum role in adolescents, compared to children, in recognizing vestibular signals with head movements during orientation in space $[13,14,15]$.

\section{CONCLUSION}

In the vestibulocerebellum high growth pace of the cortical diameter in thickness is observed in the period from birth to 3 years of age, as well as by the 


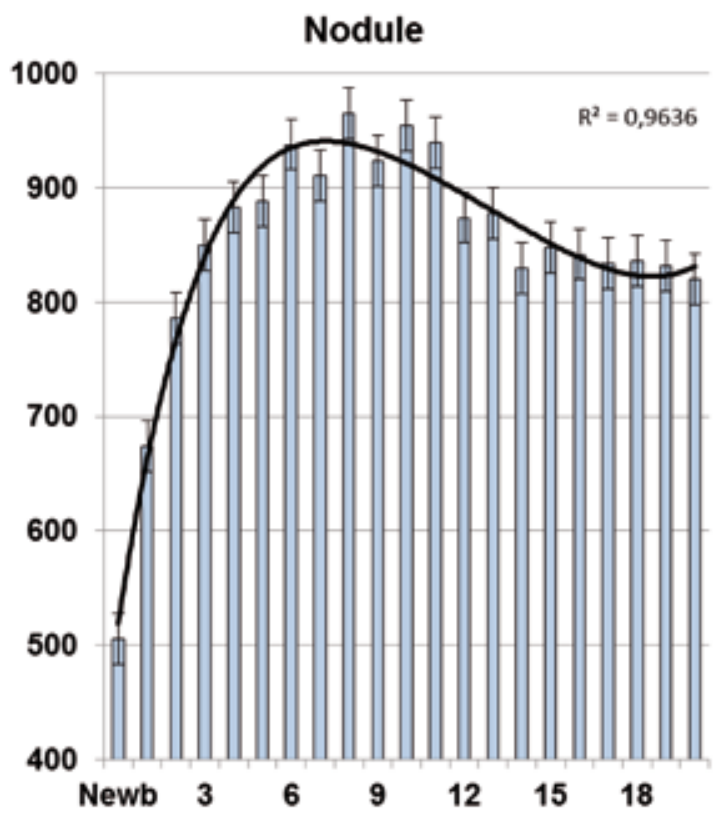

Fig. 1. Changes in the cortical thickness in the human cerebellar nodule from birth to 20 years of age

Here and on Fig. 2 and 3: on the $x$-axis - age in years, newb - newborns; on the $y$-axis - cortical thickness in $\mu$ m.

The bars represent the group means, the line represents the approximating curve of polynomial function, $R 2$ indicates the level of significance of approximation, the vertical segments represent the standard error of the mean.

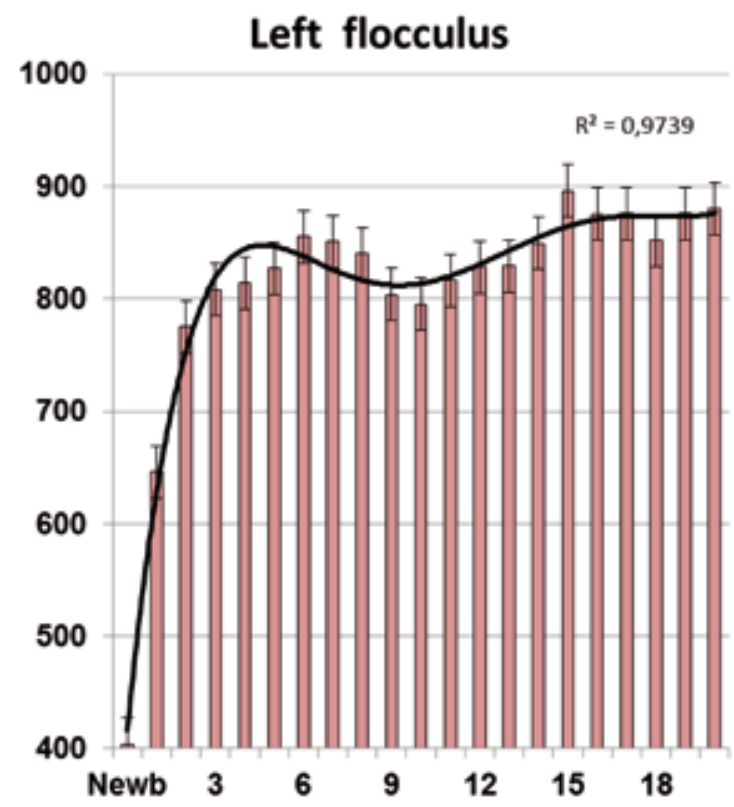

Fig. 3. Changes in the cortical thickness in the left flocculus of the human cerebellum from birth to 20 years of age

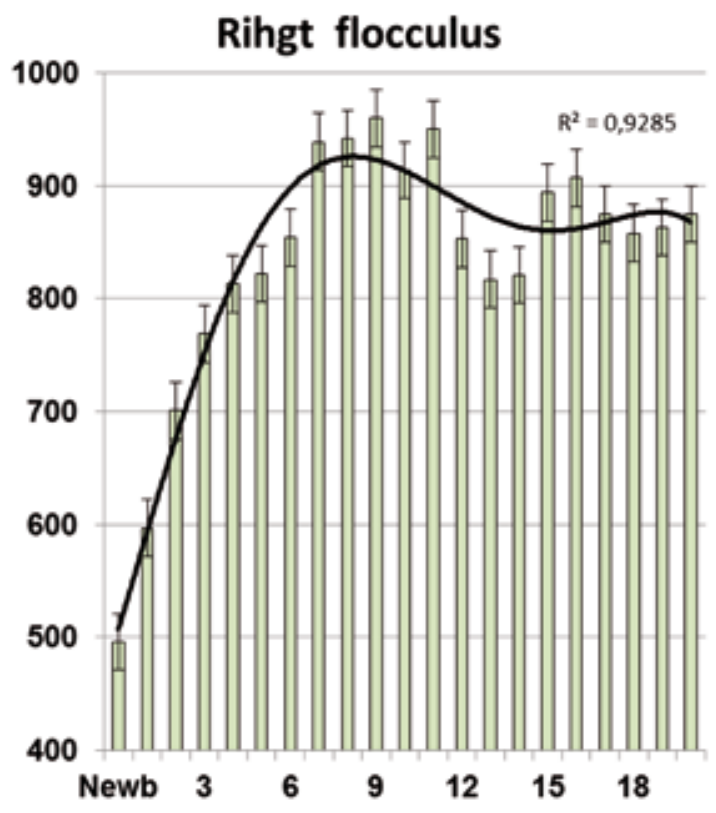

Fig. 2. Changes in the cortical thickness in the right flocculus of the human cerebellum from birth to 20 years of age

age of 7-8 years - in the nodule and the right flocculus, and by the age of 15 years - in the left flocculus. From birth to 3 years and from 9 to 11 years, there is a lateral asymmetry in the cortical thickness in the right and the left flocculi. After 15 years of age, the cortical thickness in the cerebellar flocculonodular lobe does not change on average but varies individually. The findings indicate the heterochronic maturation of hierarchically distributed multimodal integrative neural networks of the brain, involved in the motor regulation, in which the flocculi and the nodule are specifically included.

This publication was prepared with the support of the "Program of the University of People's Friendship University of 5-100" in the framework of the initiative threads № 030210-0-000.

\section{REFERENCES}

1. Habas C., Kamdar N., Nguyen D., Keller K., Beckmann C.F., Menon V., Greicius M.D. Distinct cerebellar contributions to intrinsic connectivity networks. J Neurosci. 2009. Vol. 29(26), pp. 8586-8594. doi:10.1523/JNEUROSCI.1868-09.2009.

2. Schniepp R., Möhwald K., Wuehr M. Gait ataxia in humans: vestibular and cerebellar control of dynamic stability.J Neurol. 2017. Vol.264 (Suppl 1), pp.87-92. doi: 10.1007/s00415-017-8482-3.

3. Barmack N.H. Central vestibular system: vestibular nuclei and posterior cerebellum. Brain Res Bull. 2003. Vol. 60(5-6), pp. 511-541. 
4. Iто M. Stuctural-functional relationship in cerebellar and vestibular system. Archives Italiennes de Biologie. 1991. Vol. 129, pp. 53-61.

5. Brodal A., Kawamura K. Olivocerebellar Projections: A review. Advances in Anatomy, Embryology and Cell Biology. 1980. Vol. 64, pp. 1-140.

6. Britton Z., Arshad Q. Vestibular and MultiSensory Influences Upon Self-Motion Perception and the Consequences for Human Behavior. Front Neurol. 2019. Vol.10. Article 63. 22 p. doi: 10.3389/ fneur.2019.00063.

7. Bertolini G, Ramat S, Bockisch CJ, Marti $S$, Straumann D, Palla A. Is vestibular self-motion perception controlled by the velocity storage? Insights from patients with chronic degeneration of the vestibulo-cerebellum. PLoS ONE. (2012) Vol.7, issue 6: Article e36763. doi: 10.1371/journal.pone.0036763

8. LEIGH R.J., ZEE D.S. Cerebellar influences on gaze. In: The neurology of eye movements. Fifth Edition. New York: Oxford University Press, 2015, pp. 406-416.

9. TSEкhmistrenko T.A. Sravnitel'naya harakteristika razvitiya filogeneticheski otlichayushchihsya zon kory mozzhechka cheloveka $\mathrm{v}$ postnatal'nom ontogeneze [Comparative characteristics of development in phylogenetically different areas of the human cerebellum cortex in postnatal ontogenesis]. Novye issledovaniya. [New study]. 2012, № 2 (31), pp. 63-69. (In Russ.)
10. Stefanov S.B., Kuharenko N.S. Uskorennye sposoby kolichestvennogo sravneniya morfologicheskih priznakov i system. [Accelerated methods of quantitative comparison of morphological features and systems]. Blagoveshchensk, VSKHI, 1989.65 p. (In Russ.)

11. Lyah V.I. Koordinacionnye sposobnosti: diagnostika i razvitie. [Coordination abilities: diagnosis and development]. M.: TVT Divizion, 2006. 290 p. (In Russ.)

12. Pratt M.L., Leonard H.C., Adeyinka H., Hill E.L. The effect of motor load on planning and inhibition in developmental coordination disorder. Res Dev Disabil. 2014. Vol.35 (7), pp. 1579-1587. DOI: 10.1016/j.ridd.2014.04.008.

13. Ajrezo L., Wiener-Vacher S., Bucci M.P. Saccades Improve Postural Control: A Developmental Study in Normal Children. PLOS ONE. 2013. Vol. 8, Issue 11. Article e81066. 8p. DOI: 10.1371/journal. pone.0081066

14. Olivier I., Cuisinier R., Vaugoyeau M., Nougier V., Assaiante C. Age-related differences in cognitive and postural dual-task performance. Gait Posture. 2010. Vol. 32(4), pp.494-499.

15. Palluel E., Nougier V., Olivier I. Postural control and attentional demand during adolescence. Brain Res. 2010. Vol. 1358, pp.151-159. doi: 10.1016/j. brainres.2010.08.051. 